\title{
Análise da aplicação de galerias técnicas em área integrante da operação urbana Água Branca, em São Paulo
}

\author{
Utility tunnels assessment applied to the Agua Branca \\ urban development area, in Sao Paulo, Brazil
}

\section{Luis Henrique Lancellotti Zapparolli Pupin Karin Regina de Casas Castro Marins}

\section{Resumo \\ A}

s redes que constituem os sistemas de infraestrutura urbana são, em geral, implantadas e geridas de forma isolada, sendo raramente consideradas em seu conjunto. Consequentemente, o espaço disponível no subsolo urbano tem sido reduzido, a ponto de congestionar e desorganizar sua ocupação. Nesse contexto, o presente artigo analisa e discute alternativas para a organização das redes de infraestrutura no subsolo urbano, considerando as galerias técnicas comparativamente às valas comuns. Galerias técnicas são túneis que reúnem as redes de vários serviços técnicos urbanos. A análise foi baseada na aplicação de parâmetros selecionados no caso da operação urbana Água Branca, área em desenvolvimento localizada no município de São Paulo. Os resultados mostram que as galerias técnicas representam, do ponto de vista físico e urbanístico, um meio estruturado para ocupação do subsolo e da superfície, caracterizando-se por uma alternativa eficiente, organizada e segura para a distribuição dos serviços técnicos urbanos. Do ponto de vista econômico, as galerias técnicas apresentam elevado custo inicial para implantação, o que as torna pouco viáveis quando analisadas somente sob esse critério. Em uma perspectiva de ciclo de vida, representam uma solução atraente, pelos menores custos operacionais e impactos envolvidos com a manutenção e a expansão de redes urbanas inseridas nos túneis de utilidades.

Palavras-chaves: Galerias técnicas. Serviços técnicos urbanos. Subsolo urbano, Engenharia urbana.

\footnotetext{
Abstract

Urban infrastructure networks are usually deployed and managed in an isolated form, and are rarely considered as a whole. As a consequence, the available urban underground space is increasingly reduced, resulting in congestion and disruption. This article analyses and discusses alternative ways of organizing infrastructure networks in the urban subsurface, considering utility tunnels compared to ordinary independent trenches. Utility tunnels gather several urban infrastructure networks in a single underground structure. The analysis was based on the application of selected parameters to the Agua Branca urban development area, located in Sao Paulo, Brazil. According to physical and urban planning criteria, utility tunnels represent a structured system for the occupation of the urban subsoil and surface, considering efficiency, organization and safety. From an economic perspective, technical galleries have a high initial cost of deployment making them unattractive when analysed only under this criterion. On the other hand, from a life cycle perspective, they represent an attractive solution due to their lower operation costs and the impacts involved in maintaining and expanding urban networks.

Keywords: Utility tunnels. Urban utilities. Urban subsoil. Urban engineering.
} 


\section{Introdução}

Os sistemas técnicos urbanos são compostos da infraestrutura e dos serviços públicos (MARTIRNAD, 1986). A infraestrutura corresponde às redes e equipamentos auxiliares que compõem a dimensão física, incluindo cabeamentos, tubulações, ligações domiciliares e equipamentos complementares, tais como quadros de força, válvulas, bombas, entre outros. Os serviços públicos, por sua vez, correspondem à dimensão operacional e abrangem a própria administração da infraestrutura.

As redes de infraestrutura urbana distribuem-se hoje, no Brasil, nos níveis aéreo (redes elétricas e de comunicações), superficial (redes viárias) e subterrâneo (abastecimento de água, coleta de esgoto, drenagem, gás e, em alguns casos, energia elétrica e comunicações). No entanto, com frequência essa distribuição é realizada de forma desorganizada e mesmo incompatível, tanto do ponto de vista físico quanto funcional e estético. Muitas vezes as redes se tornam sistemas frágeis ao cotidiano urbano e às intempéries, e requerem constante manutenção.

No caso do subsolo urbano, a disposição tradicional das redes urbanas em valas escavadas vem sendo questionada em virtude das dificuldades de acesso e manutenção e dos impactos sociais e econômicos correlacionados (abertura de pavimento, interrupção e desvio de tráfego, congestionamento, poluição e ruído, entre outros). Além disso, cada vez mais o subsolo urbano tem sido tratado como um recurso finito e não renovável, cuja capacidade deve ser considerada para sustentabilidade das áreas urbanas (CANTO-PERELLO; CURIELESPARZA, 2013; CANO-HURTADO; CANTOPERELLO, 1999)

Os sistemas de infraestrutura também se colocam como indispensáveis do ponto de vista social (BESNER, 2002; HUNT; ROGERS, 2005; WANG; KOIZUMI; LIU, 2008), sendo responsáveis pela provisão de serviços públicos fundamentais. Dessa forma, reforça-se a importância de coordenação de ações em planejamento e gestão urbanos e de compatibilização de soluções entre as diversas redes de infraestrutura. Ademais, o subsolo é parte do território urbano e abriga parcela considerável das instalações de serviços urbanos. Assim, deve ter seu uso, ocupação e desenvolvimento planejado e gerido de forma integrada ao restante da cidade.

Uma solução definitiva e de longo prazo para a organização das redes de infraestrutura no subsolo urbano corresponde às galerias técnicas ou túneis de utilidades, ou ainda túneis de multiutilidades (HUNT; NASH; ROGERS, 2014). Conforme descrevem Canto-Perello e Curiel-Esparza (2013), trata-se de corredores subterrâneos que contêm uma ou mais redes de infraestrutura e que permitem a instalação, manutenção e remoção desses sistemas sem realizar cortes ou escavações na superfície.

O objetivo do presente artigo é analisar e discutir alternativas para a organização das redes de infraestrutura no subsolo urbano, considerando as galerias técnicas comparativamente às valas comuns. Busca-se identificar e mensurar vantagens e desvantagens da alocação das redes segundo uma solução alternativa baseada em galerias técnicas, comparando-a à solução em valas - maneira usual de disposição das redes no subsolo urbano. Para tanto, indicadores selecionados foram aplicados em um estudo de caso, a área da operação urbana Água Branca, que atualmente está passando por um processo de desenvolvimento urbano.

\section{Galerias técnicas: conceituação e principais condicionantes}

Segundo Hunt e Rogers (2005), os termos "galeria técnica", "túnel de utilidade" ou "galeria celular" correspondem, fundamentalmente, a estruturas subterrâneas que têm como característica mais marcante a possibilidade de integrar as várias redes técnicas urbanas em um espaço comum, particionado, de simples acesso em qualquer trecho de sua extensão.

As galerias técnicas são uma solução para integrar os serviços urbanos desde épocas datadas do Império Romano, onde se locavam os condutos de fornecimento de água nos túneis escavados para os sistemas de drenagem, túneis esses caracterizados por uma grande seção transversal. Esse sistema construtivo foi esquecido durante a Idade Média e reapareceu com Haussman, nos projetos de reforma da infraestrutura de Paris em 1855 (CANO-HURTADO; CANTO-PERELLO, 1999).

Atualmente, as galerias técnicas estão presentes em diversas cidades no mundo. Laistner e Laistner (2012) exemplificam diversos tipos de galerias espalhadas em cidades como Paris, Londres, Moscou, Madri e Seattle. Nota-se grande concentração de galerias implantadas em cidades europeias. Tal fato é explicado, como descrevem Cano-Hurtado e Canto-Perello (1999),pela 
execução de um programa de engenharia urbana chamado "Eureka EU 40", financiado pela União Europeia na década de 1980 para desenvolver um novo sistema de galerias técnicas. Liderado pela França, Espanha e Itália, o programa se espalhou pela Europa e serviu como base para a construção de diversas galerias naquele continente.

Ademais, como descrito por Canto-Perello e Curiel-Esparza (2006), em geral a implantação de galerias técnicas em vários países tem sido viabilizada mediante corajosa decisão política, muitas vezes motivada pela realização de algum evento especial no país ou cidade. Nesse conceito se inserem os casos de Tóquio e Barcelona, onde a implantação de galerias técnicas foi incluída no planejamento das intervenções para jogos olímpicos.

A definição das soluções a serem adotadas para a organização do subsolo urbano e implantação das redes de infraestrutura depende de diversos condicionantes de naturezas distintas. O objetivo é garantir a oferta de serviços com eficiência, qualidade e disponibilidade, mas também minimizar transtornos ao cotidiano urbano e impactos ambientais, quando da implantação e operação das redes de infraestrutura.

\section{Condicionantes urbanísticos}

Segundo Laistner e Laistner (2012), a viabilidade da utilização das galerias técnicas depende da população que será atendida. Essa alternativa se torna mais vantajosa quanto maior a densidade populacional de uma região. $\mathrm{O}$ adensamento populacional, por sua vez, está diretamente relacionado ao processo de desenvolvimento urbano e à regulamentação do uso e ocupação do solo e do parcelamento e arruamento urbano.

Além disso, as galerias técnicas constituem uma solução que, depois de implantada, requer menos interferências no território para manutenção ou ampliação das redes. Não é necessário, para tanto, interrupções no tráfego de veículos e pedestres e reconstituição de solo e pavimento. Dessa forma, essa alternativa traz menos impactos à estrutura urbana e contribui para a conservação dos demais sistemas subterrâneos e também dos superficiais.

As galerias técnicas, entre outras aplicações, podem ser alocadas em áreas que estejam sujeitas a processos de desenvolvimento urbano ou reurbanização, como operações urbanas e concessões urbanísticas. Locais onde está previsto adensamento populacional, ampliação da capacidade de redes de infraestrutura ou intervenções no sistema viário e na pavimentação, por exemplo, tornam-se áreas potenciais para a aplicação das galerias técnicas.

\section{Condicionantes físicos}

As galerias técnicas devem ser implantadas de forma a satisfazer as condições de operação dos serviços técnicos urbanos.

Em geral, o espaço reservado dentro dos túneis deve estar de acordo com a capacidade e as dimensões das redes a serem implantadas e devem, também, possibilitar a locomoção e o trabalho dos técnicos responsáveis pela manutenção e ampliação das redes, além de se considerar o espaço necessário para ampliações futuras, como descrevem Hunt e Rogers (2005). Deve-se também levar em consideração a distribuição correta das redes para que não haja interferências; por exemplo, os cabos de energia elétrica devem ser posicionados afastados dos cabos de distribuição de dados.

Existem, basicamente, dois tipos de túneis para a estruturação de galerias técnicas, como descrito por Cano-Hurtado e Canto-Perello (1999): o primeiro, chamado de "galerias técnicas visitáveis" (visitable), permite a locomoção de pessoas em seu interior e é composto de túneis de maiores dimensões; o segundo, chamado de "galerias técnicas de pesquisa" (searchable), apresenta seções transversais menores e não garante a locomoção de pessoas em seu interior, por toda sua extensão. A escolha do tipo de galerias técnicas se dá logo no início do projeto. Os túneis de pesquisa são geralmente utilizados nas seções finais de distribuição, logo antes da conexão com as construções. Os túneis visitáveis são utilizados no transporte principal dos serviços ou, também, quando há necessidade de uma seção maior para alocar as redes.

Do ponto de vista estrutural, os túneis de utilidades são formados por uma "casca", que pode ser feita com diferentes materiais, destacando-se o aço e o concreto. As cascas de concreto podem ser moldadas no local ou ser pré-moldadas (CANTOPERELLO; CURIEL-ESPARZA, 2006). Para a decisão do material e métodos construtivos a serem utilizados, deve-se realizar uma pesquisa sobre os custos atuais do mercado, assim como as características da região onde as galerias serão implantadas. Devido ao uso mais habitual do concreto, as galerias técnicas confeccionadas com esse material podem ser mais favoráveis no mercado brasileiro.

A escolha do local para a implantação de galerias técnicas deve considerar ainda as dificuldades impostas pela geologia, topografia e ocupação do terreno. Locais onde há grande ocupação por 
construções que utilizam o subsolo, ou onde a tipologia geológica do solo dificulta a implantação dos túneis, podem elevar o custo de implantação, seja devido a custos com escavação, seja em virtude dos custos decorrentes da reorganização das estruturas subterrâneas para alocar as galerias técnicas (HUNT; NASH; ROGERS, 2014). A topografia se torna mais relevante quando os tubos de drenagem se inserem dentro das galerias; porém, devido às dimensões comumente utilizadas para esse propósito, sua inserção dentro dos túneis se torna praticamente inviável, sendo esses, portanto, alocados separadamente. O mesmo ocorre para equipamentos auxiliares, como bombas e transformadores de energia, que são, geralmente, alocados fora das galerias.

\section{Condicionantes de gestão}

As galerias técnicas propiciam um ambiente organizado e compatibilizado, que necessita ser compartilhado entre as diversas entidades prestadoras dos serviços e órgãos públicos gestores, o que demanda maior contato entre as instituições que venham a dividir um mesmo ambiente para alocação de suas redes. CantoPerello e Curiel-Esparza (2013) destacam que a grande quantidade de instituições governamentais e privadas envolvidas na prestação dos serviços públicos e gestão da infraestrutura urbana dificulta a ação coordenada sobre as redes.

Canto-Perello e Curial-Esparza (2006) mencionam que no gerenciamento das galerias técnicas é necessário levar em consideração dois fatores: a lealdade entre as diversas empresas responsáveis pelas redes inseridas; e a segurança do trabalhador dentro das galerias. A lealdade envolve a cooperação entre os trabalhadores de cada utilidade pública, que devem realizar somente o trabalho que estão capacitados a fazer, não interferindo em redes que não sejam de sua responsabilidade. Para os autores, "a lealdade é um dos maiores problemas para muitas companhias que dividem o mesmo espaço com outras", porém mencionam que já existem medidas que visam mitigar esse problema. Outro ponto relevante é assegurar as condições de segurança para o trabalhador na galeria. Para Canto-Perello e Curial-Esparza (2006), deve-se tomar medidas que garantam que o ambiente de trabalho esteja adequado, tais como instalar detectores de fumaça, de inundação, de elevação da temperatura e de emissão de monóxido de carbono, assim como ter saídas de emergência e desligamento automático das redes. Além das medidas relacionadas ao ambiente, o trabalhador deve estar capacitado e ciente dos riscos envolvido no trabalho a ser realizado no interior das galerias.
Para Canto-Perello e Curiel-Esparza (2013), a estrutura organizacional e aspectos de lealdade configuram, do ponto de vista da governança, as principais barreiras para a implementação de galerias técnicas. Os autores defendem que deve haver uma instituição responsável pela gestão da galeria técnica, que responda por sua segurança, controle de acesso, operação e manutenção ao longo de todo o período de utilização. Esse gerenciamento pode ser assumido por um departamento municipal relacionado a serviços públicos, ou pode ser criada uma autoridade específica para a gestão dos túneis de utilidades. Os autores mencionam ainda que, no caso de propriedade privada das redes, uma das empresas envolvidas pode assumir a função de supervisão de todo o sistema.

\section{Condicionantes econômicos}

Uma das maiores dificuldades para a implantação de galerias técnicas, além dos aspectos inerentes à gestão compartilhada, é o custo inicial. Quando se analisam os custos de implantação de redes de modo convencional, ou seja, enterradas em valas separadas, nota-se que é substancialmente menor que o desprendido com a implantação de galerias técnicas (CANTO-PERELLO; CURIELESPARZA, 2013; HUNT; NASH; ROGERS, 2014). As galerias técnicas, além do investimento na própria estruturação do túnel, requerem sistemas adicionais, tais como ventilação, iluminação, drenagem, comunicações, alarmes, sistemas de escape, que contribuem para elevar o custo inicial (CANTO-PERELLO; CURIELESPARZA, 2013).

Entretanto, ao se analisar o custo no decorrer dos anos, as galerias técnicas se apresentam muito mais vantajosas. Um estudo realizado por Laistner e Laistner (2012) em diversas cidades na Europa mostrou que os custos operacionais anuais das redes dos diversos serviços técnicos urbanos são razoavelmente menores, o que favorece a utilização dessa alternativa quando se analisam horizontes de planejamento maiores. Como exemplo, os autores citam a cidade de Leipzig, na Alemanha, onde se verificou um custo anual de operação dos serviços de distribuição de água, energia elétrica, comunicação e coleta de esgoto cerca de 3,4 vezes maior quando se utilizam valas segregadas para a alocação das redes de infraestrutura, comparativamente às galerias técnicas. Nesse mesmo estudo, a cidade que apresentou a menor diferença ao se analisarem os custos com a adoção de cada alternativa foi Laucchein, onde os custos anuais de operação dos serviços técnicos urbanos ficaram cerca de 2 vezes mais elevados ao se utilizar a alternativa comum 
de alocação em relação à utilização de galerias técnicas. Conclui-se, portanto, que, durante o planejamento desses sistemas, torna-se necessária a verificação em longo prazo das alternativas, para que seja escolhida aquela que apresente menores impactos e custos globais ao longo do ciclo de vida. Laistner e Laistner (2012) destacam ainda a durabilidade das redes inseridas nas galerias técnicas e mencionam que há tubos e cabos que resistem por mais de 100 anos dentro de túneis de utilidades. Essa grande durabilidade é determinada pelo ambiente proporcionado pelas galerias técnicas - protegido, previsível e não agressivo -, o que garante a tubulações e cabos nestas inseridos grande durabilidade e minimiza a execução de manutenções.

Para Canto-Perello e Curiel-Esparza (2013), existem ainda muitos benefícios adicionais associados à solução em galerias técnicas de difícil mensuração e que apresentam bastante relevância. Eles envolvem, por exemplo, o tempo economizado por não ter de abrir o pavimento, escavar e reaterrar o subsolo para manutenção das redes e a redução dos acidentes decorrentes da execução dessas intervenções.

Da análise dos condicionantes tratados, verifica-se que, apesar de se configurar uma solução adequada ao ambiente e aos sistemas técnicos urbanos, as galerias técnicas demandam planejamento adicional e estratégias de gestão urbana que garantam o alcance das diversas vantagens mencionadas. A adequada análise do meio onde as galerias técnicas serão inseridas é de suma importância para que essa solução se torne vantajosa diante dos sistemas comuns de alocação da infraestrutura e possa agregar durabilidade, segurança e confiabilidade aos serviços e às redes inseridas no interior dos túneis. Conforme mencionado, uma das grandes dificuldades da opção pelas galerias técnicas reside na gestão do espaço, que é compartilhado por múltiplas entidades prestadoras de serviços, o que requer esforços adicionais no sentido de regular e fiscalizar as atividades dos entes envolvidos. Somado a esse fator, tem-se o elevado custo inicial de implantação das galerias técnicas, fazendo-se necessária a análise de viabilidade econômica em longo prazo e a consideração de custos de ciclo de vida nos processos de tomada de decisão.

\section{Análise da aplicação de galerias técnicas em área integrante da operação urbana Água Branca, em São paulo}

A área da operação urbana Água Branca está localizada na região da Barra Funda, em São Paulo. Está próxima ao centro de São Paulo e é facilmente acessível pelas rodovias Castelo Branco, Anhanguera ou Bandeirantes e avenidas Marginais do Tietê e Marquês de São Vicente. Abrange $5,40 \mathrm{~km}^{2}$. Apresentava densidade média de 36 habitantes por hectare em 2008, ou seja, uma população total de cerca de 19.440 habitantes, quando foi desenvolvido o plano urbanístico para a área, coordenado pela Empresa Municipal de Urbanização (2009).

Do ponto de vista urbanístico e físico, o plano urbanístico prevê grande adensamento populacional no médio prazo para a área, podendo chegar a 200 habitantes por hectare, dependendo do setor de desenvolvimento. Como se trata de uma área que ainda permite o parcelamento do solo, dada a existência de algumas glebas e quadras de grandes dimensões, ocupadas por instalações industriais e transportadoras, as quais podem ser divididas, as galerias técnicas podem configurar uma solução atraente para organizar o subsolo urbano nessa área, a qual foi selecionada, portanto, como estudo de caso para proceder à análise em questão.

\section{Premissas}

Foram consideradas duas soluções básicas de infraestrutura urbana com vistas à organização das redes no subsolo urbano.

Foi definida uma situação de referência no que diz respeito à alocação dos serviços técnicos urbanos, para isso assumida sua inserção em valas segregadas.

A solução alternativa considerada, por sua vez, refere-se a galerias técnicas moldadas in loco. Esta solução foi selecionada pelo fato de a área da Água Branca ser várzea, com lençol freático raso, e a execução da estrutura no local da obra permitir realizar a impermeabilização de forma mais otimizada, sem necessitar de arremates aduela a aduela, no caso da opção por pré-moldados. É preciso considerar, no entanto, que a execução de uma obra com essa extensão traria impactos no entorno e no sistema viário, o que poderia ser minimizado com a execução por trechos/setores, com desmobilização e liberação gradual para uso. Existem outras formas de execução das galerias técnicas, tais como uso de anéis pré-moldados de 
concreto, laje invertida ou minituneladoras, que impactariam nos custos da solução e que poderiam ser considerados também como opções em outras áreas ou estudos.

Para o estudo da região, partiu-se da divisão da área em nove setores (A a I), conforme definido pela Empresa Municipal de Urbanização (2009). Para cada setor foram consideradas as respectivas densidades populacionais e características de uso e ocupação do solo propostas no plano urbanístico da operação urbana. Assumiu-se, ainda, que as redes serão alocadas no perímetro de cada setor, sendo subdivididas em trechos, o mesmo ocorrendo com as galerias técnicas, conforme indicado na Figura 1. Tal suposição se fez necessária por haver a informação da densidade populacional por setor, sendo possível, assim, determinar a população que cada trecho de rede irá atender. Além disso, acredita-se que essa poderia representar uma estratégia de execução dos túneis de utilidades, por trechos e setores, que liberaria gradativamente as áreas para uso.

Para determinação da área de atendimento de cada trecho de rede, cujos comprimentos estão especificados na Tabela 1, dividiu-se a área total ponderando-se o comprimento da tubulação em relação ao comprimento total do perímetro do setor. Dessa forma, tubulações mais longas atendem a uma área proporcionalmente maior quando comparadas a tubulações mais curtas, uma vez que cada seção é responsável pelo fornecimento de água para seu entorno. Além disso, trechos de tubulações que são comuns a mais de um setor, como o trecho 6-7, que é comum aos setores A e B, devem atender às parcelas da população dos setores adjacentes, o que implica a necessidade de diâmetros maiores de tubulação.

Da somatória dos trechos indicados, seriam, portanto, instalados 20.126,64 $\mathrm{m}$ de galerias, ou seja, mais de $20 \mathrm{~km}$ de túneis de utilidades, o que configuraria uma obra com importantes repercussões em escala urbana.

\section{Metodologia}

Com base na revisão bibliográfica, foram selecionados parâmetros técnicos e econômicos que permitissem comparar duas soluções, as galerias técnicas e as valas comuns segregadas, para organização das redes de infraestrutura em subsolo urbano na área do estudo de caso, a operação urbana Água Branca. Para isso, buscouse utilizar referências para uma estimativa em macroescala, contabilizando os principais elementos que pudessem impactar na composição de custos das duas soluções consideradas.

\section{Figura 1 - Localização da operação urbana Água Branca, no município de São Paulo, e divisão da área} em setores e trechospara traçado das galerias técnicas

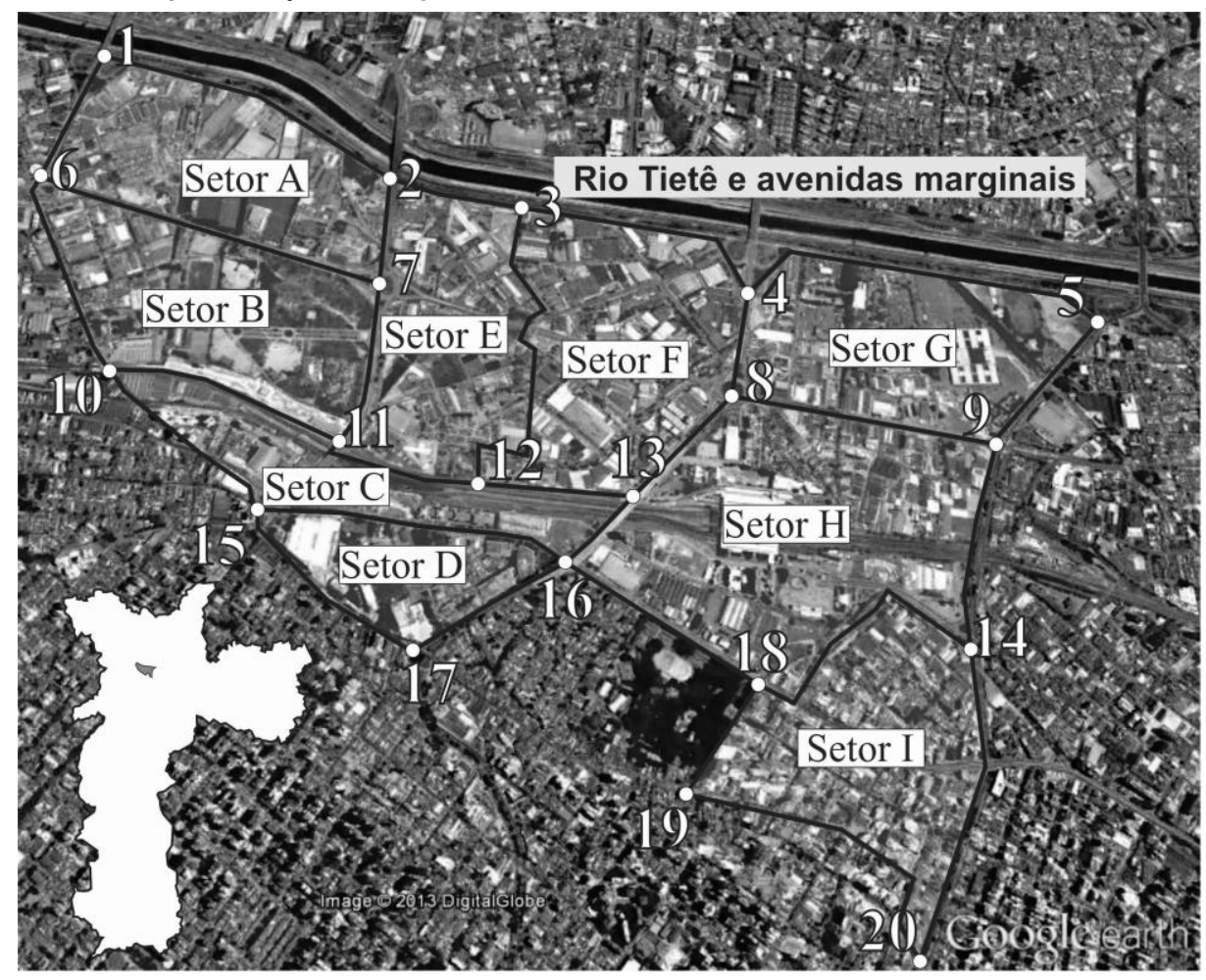

Fonte: adaptada de Google (2013). 
Tabela 1 - Trechos: comprimento e setores de atendimento

\begin{tabular}{|c|c|c|c|c|c|}
\hline Trecho & Setor atendido & Comprimento (m) & Trecho & Setor atendido & Comprimento (m) \\
\hline 12 & A & 1014,83 & 27 & A e E & 388,54 \\
\hline 23 & $\mathrm{E}$ & 444,35 & 312 & E e F & 1351,89 \\
\hline 34 & $\mathrm{~F}$ & 892,71 & 48 & $\mathrm{~F}$ e $\mathrm{G}$ & 269,8 \\
\hline 45 & $\mathrm{G}$ & 1221,91 & 59 & $\mathrm{G}$ & 575,37 \\
\hline 67 & $\mathrm{~A}$ e B & 1057,64 & 610 & B & 765,33 \\
\hline 89 & $\mathrm{Ge} \mathrm{H}$ & 813,93 & 711 & B e E & 601,83 \\
\hline 1011 & $\mathrm{~B}$ e $\mathrm{c}$ & 824,65 & 813 & $\mathrm{Fe} \mathrm{H}$ & 537,88 \\
\hline 1112 & $\mathrm{E}$ e C & 434,26 & 914 & $\mathrm{H}$ & 854,04 \\
\hline 1213 & $\mathrm{~F}$ e $\mathrm{C}$ & 481,06 & 1015 & $\mathrm{C}$ & 712,89 \\
\hline 1516 & C e D & 924,14 & 1316 & $\mathrm{Ce} \mathrm{H}$ & 251,89 \\
\hline 1618 & $\mathrm{H}$ & 648,04 & 1517 & $\mathrm{D}$ & 763,6 \\
\hline 1814 & $\mathrm{H}$ e I & 854,04 & 1617 & $\mathrm{D}$ & 496,22 \\
\hline 1920 & I & 865,02 & 1819 & I & 390,28 \\
\hline 16 & A & 639,18 & 1420 & I & 1051,32 \\
\hline
\end{tabular}

Relativamente aos parâmetros técnicos, foram utilizados dados da Associação Brasileira de Tubos de Concreto (ASSOCIAÇÃO..., 2012) para estimar a execução das galerias técnicas, assim como parâmetros indicados por Rubens (2011), relativamente à abertura de valas e recomposição de pavimento. No que diz respeito às redes de infraestrutura, devido à dificuldade na obtenção de dados de referência sobre custos de todos os sistemas passíveis de inserção nas galerias técnicas, foram considerados os sistemas de abastecimento de água e de fornecimento de energia elétrica, que, além de terem dados disponíveis, constituem redes indispensáveis em áreas urbanas adensadas. Para estimativa do sistema de abastecimento de água, foram utilizados parâmetros de consumo de água no município de São Paulo relativamente a 2010 e publicados pelo Sistema Nacional de Informação sobre Saneamento (SISTEMA..., 2012), além do método de pré-dimensionamento de rede apresentado por Rubens (2011). Com relação à rede de energia elétrica, utilizaram-se os procedimentos de prédimensionamento disponibilizados por Velasco, Lima e Couto (2006).

Para a obtenção dos custos unitários de obras e realização de composição de custos de investimentos, foram utilizados dados publicados pela Prefeitura de São Paulo/Secretaria de Infraestrutura Urbana e de Obras (SECRETARIA..., 2014, data-base de janeiro de 2014) e pelo Sistema Nacional de Custos e Índices da Construção Civil para o Estado de São Paulo (SISTEMA..., 2013a, 2013b, data-base de abril de 2013). A escolha dessas fontes está relacionada à disponibilidade de dados para estimativa das obras de infraestrutura urbana, aplicáveis ao município de São Paulo.
A análise comparativa incluiu também os custos de operação das redes inseridas nas duas condições de implantação, sendo nesse caso adotados valores médios referentes a experiências internacionais, conforme Laistner e Laistner (2012), devido à carência de referências nacionais que pudessem suportar as estimativas relativas aos custos operacionais das soluções analisadas.

\section{Situação de referência: solução em valas}

\section{Distribuição de água}

Com relação à rede de distribuição de água, assumiu-se uma estrutura em forma de malha (ou anéis), posicionada nos limites de cada setor.

Considerando-se a área de atendimento de cadatrecho da tubulação, determinada pela distribuição das áreas dos setores entre os trechos da malha adjacente, e com basena densidade populacional de cada setor, foi estimada a quantidade de habitantes a serem atendidos por cada trecho da rede de distribuição de água. Para o cálculo da demanda de água em cada trecho, por sua vez, foi considerado o consumo médio por habitante em São Paulo, que, segundo o Sistema Nacional de Informação sobre Saneamento (2012), era de 184,7 litros por habitante por dia em 2010, majorado pelo coeficiente diário de maior consumo $(1,2)$ e pelo coeficiente da hora de maior consumo (1,5) (RUBENS, 2011).

Com as vazões estabelecidas, foram adotadas as velocidades máximas e mínimas permitidas pela NBR 12118 (ABNT, 1994). Para estimar o diâmetro das tubulações. Considerando os diâmetros comerciais disponíveis para tubulações (50 mm, $75 \mathrm{~mm}, 100 \mathrm{~mm}, 150 \mathrm{~mm}$ e $200 \mathrm{~mm}$ ), 
determinou-se o diâmetro necessário para cada trecho.

$\mathrm{Na}$ análise dos custos de implantação da rede de distribuição de água foram incluídos os custos referentes aos serviços e aos materiais, tomando-se como referência o Sistema Nacional de Custos e Índices da Construção Civil (Sinapi), para o Estado de São Paulo, com data-base de 30 de abril de 2013. Os custos com serviços incluem abertura, fechamento e compactação da vala; carga, transporte e descarga de material; e assentamento da tubulação e remoção e recomposição do pavimento sob o qual se assentará a rede. Há outros custos com serviços complementares de difícil quantificação, como interrupções no tráfego, limpeza da área, rebaixamento do lençol freático (quando necessário), entre outros, que não foram considerados neste estudo. Para os custos com materiais foi considerada a utilização de tubos de PVC, porém não há restrições para a adoção de dutos de outros materiais disponíveis no mercado.

Os custos referentes à movimentação de terra são comuns para todas as tubulações. Segundo Rubens (2011), para tubulações de $50 \mathrm{~mm}$ a $150 \mathrm{~mm}$ de diâmetro, como aquelas presentes na área em estudo, a largura da vala deve ser de $0,5 \mathrm{~m}$. A profundidade, por sua vez, é função do tipo de pavimentação sob a qual a rede será alocada; para a região estudada, assumiram-se dutos instalados sob o leito viário pavimentado e, para tanto, necessita-se de um recobrimento de $1,0 \mathrm{~m}$ da tubulação.

Os custos com pavimentação são estimados a partir da composição e da quantidade de material utilizado. Na presente análise, foi adotado um volume médio de tráfego de veículos, que, de acordo com Rubens (2011) deve apresentar uma pavimentação composta de $10 \mathrm{~cm}$ de macadame hidráulico, $7 \mathrm{~cm}$ de binder e $5 \mathrm{~cm}$ de concreto asfáltico, conforme esquema apresentado na Figura 2.

Dos custos descritos, são calculados os valores desprendidos com todos os trechos de tubulação. Para tanto, consideraram-se os serviços envolvidos na abertura e fechamento de cada vala correspondente a cada trecho em estudo. A Tabela 2 mostra os custos unitários e totais desprendidos com os serviços de abertura e fechamento das valas.

Para custos referentes à aquisição e movimentação da tubulação, somou-se o comprimento total dos tubos, por diâmetro de tubulação. Por exemplo, para tubulações de $50 \mathrm{~mm}$ de diâmetro, tem-se um comprimento total de $4.541,84 \mathrm{~m}$. Com esse comprimento é possível quantificar o custo total envolvido para a inserção das tubulações desse diâmetro,a partir dos custos unitários de aquisição, transporte e assentamento. A Tabela 3 mostra os valores unitários e totais referentes aos diâmetros utilizados no estudo.

Em síntese, para cada trecho foram estimados os seguintes custos de investimento:
(a) custos com remoção e transporte da pavimentação existente;
(b) custo total com movimentação de terra;
(c) custo com repavimentação;
(d) custo de aquisição dos tubos;
(e) custo com transporte de tubos; e
(f) custo com assentamento de tubos.

Com a somatória dos custos totais de cada trecho, obteve-se o custo total de $\mathrm{R} \$ 1.368 .023,13$, para implantação da rede de distribuição de água na região de estudo.

Figura 2 - Esquema da tubulação de água sob o pavimento (em metros)

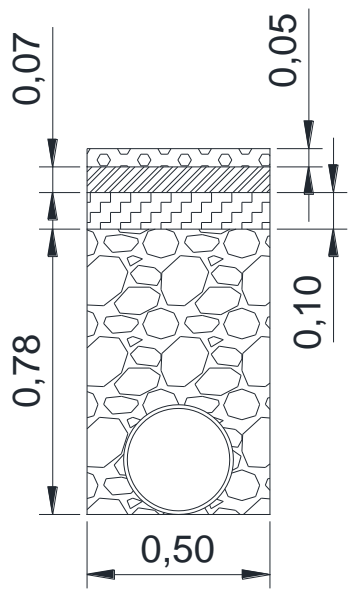

\begin{tabular}{|l|l|}
\hline & Binder \\
\hline & Reaterro \\
\hline & Tubulacão \\
\hline
\end{tabular}

70 Pupin, L. H. L. Z.; Marins, K. R. de C. C. 
Tabela 2 - Custos de serviços unitários e totais para a rede de distribuição de água

\begin{tabular}{l|c|c|c|r}
\multicolumn{1}{c|}{ Serviço } & Unidade & $\begin{array}{c}\text { Custo } \\
\text { (R\$lunidade) }\end{array}$ & $\begin{array}{c}\text { Quantidade } \\
\text { (unidade) }\end{array}$ & $\begin{array}{c}\text { Custo } \\
\text { total (R\$) }\end{array}$ \\
\hline $\begin{array}{l}\text { Escavação mecânica de valas em qualquer tipo de } \\
\text { solo, exceto rochas, prof. < 4 m }\end{array}$ & $\mathrm{m}^{3}$ & 7,01 & $9.560,15$ & $67.016,68$ \\
\hline Reaterro e compactação mecânica de vala & $\mathrm{m}^{3}$ & 18,06 & $7.714,36$ & $139.321,43$ \\
\hline $\begin{array}{l}\text { Carga, transporte e descarga mecânica de material } \\
\text { até 10 km }\end{array}$ & $\mathrm{m}^{3}$ & 8,60 & $2.556,17$ & $21.983,06$ \\
\hline $\begin{array}{l}\text { Demolição de pavimento asfáltico, inclusive capa; } \\
\text { inclui carga em caminhão }\end{array}$ & $\mathrm{m}^{2}$ & 9,98 & $10.063,32$ & $100.431,93$ \\
\hline $\begin{array}{l}\text { Execução macadame hidráulico; inclui transporte } \\
\text { de material }\end{array}$ & $\mathrm{m}^{3}$ & 156,66 & $1.006,33$ & $157.651,97$ \\
\hline Execução binder & $\mathrm{m}^{3}$ & 313,45 & 704,43 & $220.804,34$ \\
\hline Execução concreto asfáltico & $\mathrm{m}^{3}$ & 446,02 & 503,17 & $224.422,10$ \\
\hline Transporte de material, binder e concreto asfáltico & $\mathrm{m}^{3}$ & 7,36 & $1.207,60$ & $8.887,92$ \\
\hline
\end{tabular}

Fonte: adaptado de Sistema Nacional de Pesquisa ee Índices da Construção Civil (2013a).

\section{Distribuição de energia elétrica}

A alocação da rede de distribuição de energia foi realizada da mesma forma que a rede de abastecimento de água, ou seja, no perímetro de cada setor. Foi considerada, ainda, a execução do recapeamento da mesma maneira descrita para a execução da rede de distribuição de água.

Como descrito para a rede de abastecimento de água, os custos de investimento a serem considerados para a execução de uma rede subterrânea de distribuição de energia se dividem em custo de serviços e custos de materiais.

Velasco, Lima e Couto (2006) especificam que, para a execução de $1 \mathrm{~km}$ de rede elétrica, são necessários $1.000 \mathrm{~m}$ de cabo de $240 \mathrm{~mm}^{2}$ de cobre, $50 \mathrm{~m}$ de cabo de $240 \mathrm{~mm}^{2}$ de alumínio armado, 2 conjuntos de terminais de alta tensão e 1 conjunto de transformadores em pedestal de $300 \mathrm{kVA}$, além de obras civis de execução da vala e recapeamento.

A Tabela 4 apresenta os custos unitários e totais dos serviços e materiais estimados para a rede de distribuição de energia elétrica.

Em resumo, considerando os custos envolvidos na implantação da rede de energia elétrica na região da operação urbana Água Branca, chegou-se a um custo total de $\mathrm{R} \$ 8.800 .881,39$.

\section{Situação alternativa: solução em galerias técnicas}

A situação alternativa baseia-se na utilização de galerias técnicas para alocar as redes de energia elétrica e de abastecimento de água, as quais também foram consideradas posicionadas no perímetro de cada setor.
Para o estudo de caso em questão, foi considerada a execução in loco de uma galeria de 2,0 m por 2,0 $\mathrm{m}$, e um aterro sobre a laje superior composto de 0,10 $\mathrm{m}$ de macadame hidráulico, 0,07 $\mathrm{m}$ de binder e $0,05 \mathrm{~m}$ de concreto asfáltico, conforme representado na Figura 3. As dimensões das galerias foram adotadas de modo a garantir o espaço necessário para alocação das redes de serviços técnicos em seu interior.

Com a utilização das galerias técnicas, serviços como quebra de pavimentação existente, escavação de vala e recapeamento são realizados apenas uma vez. Com essa alternativa, o custo de implantação das redes nos túneis fica simplificado, além da aquisição de material e da alocação destes dentro das galerias, o que representa uma pequena parcela do custo total de implantação. Para a locação das galerias, considerou-se uma folga de $10 \mathrm{~cm}$ de cada lado das células, o que implica uma vala com 2,2 m de largura.

Para estimar a fabricação das galerias in loco, foram assumidas as quantidades de materiais explicitadas em ABTC (ASSOCIAÇÃO..., 2012) e os custos informados na Tabela de custos com desoneração da Siurb, data-base janeiro de 2014 (SECRETARIA..., 2014). Os custos envolvidos na fabricação de $1 \mathrm{~m}$ linear de galerias técnicas estão mostrados na Tabela 6 .

Para os custos de quebra da pavimentação existente, transporte de entulhos e recapeamento, foram adotados os mesmos valores unitários utilizados para a rede de distribuição de água e energia elétrica. Acresce-se a esses custos o relacionado com o escoramento da vala em madeira com reaproveitamento que, segundo Siurb (SECRETARIA..., 2014), é de R \$ 55,98 por metro quadrado de talude escorado. 
Tabela 3 - Custos unitários e totais dos materiais e serviços referentes à tubulação de PVC

\begin{tabular}{|c|c|c|c|c|}
\hline $\begin{array}{c}\text { Serviço ou } \\
\text { material }\end{array}$ & $\begin{array}{c}\text { Diâmetro } \\
(\mathbf{m m})\end{array}$ & $\begin{array}{c}\text { Custo } \\
(\mathbf{R} \$ / \mathrm{m}) \\
\end{array}$ & $\begin{array}{c}\text { Quantidade } \\
\text { (m) }\end{array}$ & $\begin{array}{c}\text { Custo } \\
\text { total (R\$) }\end{array}$ \\
\hline \multirow{4}{*}{$\begin{array}{l}\text { Transporte de } \\
\text { tubos de PVC }\end{array}$} & 50 & 0,09 & $4.541,84$ & 408,77 \\
\hline & 75 & 0,14 & $8.228,43$ & $1.151,98$ \\
\hline & 100 & 0,18 & $4.099,12$ & 737,84 \\
\hline & 150 & 0,14 & $3.257,25$ & 456,02 \\
\hline \multirow{4}{*}{$\begin{array}{l}\text { Assentamento } \\
\text { de tubos de } \\
\text { PVC }\end{array}$} & 50 & 0,94 & $4.541,84$ & $4.269,33$ \\
\hline & 75 & 1,25 & $8.228,43$ & $10.285,54$ \\
\hline & 100 & 1,57 & $4.099,12$ & $6.435,62$ \\
\hline & 150 & 1,88 & $3.257,25$ & $6.123,63$ \\
\hline \multirow{4}{*}{$\begin{array}{l}\text { Tubulação de } \\
\text { PVC }\end{array}$} & 50 & 8,33 & $4.541,84$ & $37.833,53$ \\
\hline & 75 & 13,06 & $8.228,43$ & $107.463,30$ \\
\hline & 100 & 27,74 & $4.099,12$ & $113.709,59$ \\
\hline & 150 & 42,56 & $3.257,25$ & $138.628,56$ \\
\hline & & & Total & $427.503,69$ \\
\hline
\end{tabular}

Fonte: adaptado de Sistema Nacional de Pesquisa e Índices da Construção Civil (2013a, 2013b).

Tabela 4 - Custos de materiais e serviços unitários e totais da rede de energia elétrica

\begin{tabular}{l|c|c|r|r|r}
\hline \multicolumn{1}{c|}{ Material ou serviço } & Unidade & $\begin{array}{c}\text { Quantidade } \\
\text { por km } \\
\text { (unidades) }\end{array}$ & $\begin{array}{c}\text { Quantidade } \\
\text { total } \\
\text { (unidades) }\end{array}$ & $\begin{array}{c}\text { Custo } \\
\text { (R\$/unidade) }\end{array}$ & $\begin{array}{c}\text { Custo total } \\
(\mathbf{R} \$ \text { ) }\end{array}$ \\
\hline Cabo de cobre $240 \mathrm{~mm}^{2}$ & $\mathrm{~m}$ & $1.000,00$ & $20.126,64$ & 74,93 & $1.508 .168,64$ \\
Cabo de alumínio $240 \mathrm{~mm}^{2}$ & $\mathrm{~m}$ & 50,00 & $1.006,33$ & 49,63 & $49.945,06$ \\
Terminal de alta tensão & unidade & 2,00 & 41,00 & 374,90 & $15.370,70$ \\
Transformador em pedestal & unidade & 1,00 & 21,00 & $15.445,81$ & $324.362,01$ \\
Via asfáltica (obra civil) & $\mathrm{m}$ & $1.000,00$ & $20.126,64$ & 174,55 & $3.513 .105,01$ \\
Vala em via asfáltica (obra civil) & $\mathrm{m}$ & $1.000,00$ & $20.126,64$ & 168,43 & $3.389 .929,98$ \\
\hline
\end{tabular}

Fonte: adaptado de Sistema Nacional de Pesquisa e Índices da Construção Civil(2013b) e Velasco, Lima e Couto (2006).

Figura 3 - Esquema da galeria técnica adotada para a solução alternativa (em metros)

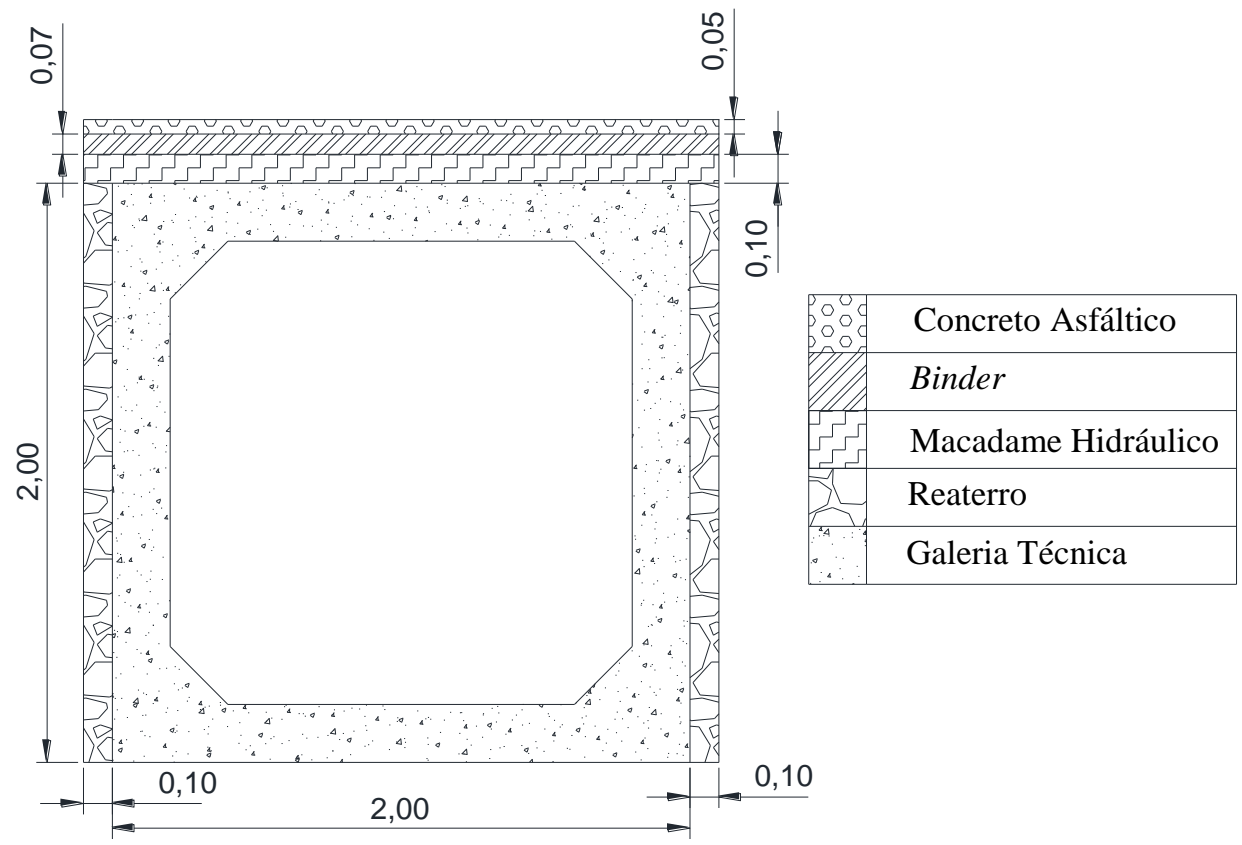

72 Pupin, L. H. L. Z.; Marins, K. R. de C. C. 
Tabela 5 - Custos de materiais para fabricação de $1 \mathrm{~m}$ linear de galerias técnicas

\begin{tabular}{l|c|c|c|c}
\hline \multicolumn{1}{c|}{ Material } & Unidade & Quantidade & Custo Unitário & Custo Total \\
\hline Aço CA50 & $\mathrm{kg}$ & 28,63 & 6,13 & 175,51 \\
Tela Aço CA60 & $\mathrm{kg}$ & 60,83 & 5,89 & 358,29 \\
Concreto & $\mathrm{m}^{3}$ & 1,19 & 324,64 & 386,32 \\
Forma & $\mathrm{m}^{2}$ & 14,32 & 36,06 & 516,38 \\
Cimbramento & $\mathrm{m}^{3}$ & 1,19 & 26,48 & 31,51 \\
\hline \multicolumn{5}{|r|}{} \\
\hline
\end{tabular}

Fonte: adaptado de Secretaria de Infraestrutura Urbana e de Obras (2014).

Com os parâmetros enunciados acima, o custo total da implantação das galerias técnicas foi estimado em R $\$ 38.532 .212,17$ para um comprimento total de 20.126,64 $\mathrm{m}$ de galerias, conforma somatório dos trechos indicados na Tabela 1. Dessa forma, obteve-se um valor médio de R\$ 1.914,49 por metro linear para implementação de túneis de utilidades para o estudo de caso em questão. Nesse valor estão excluídos os custos com as próprias redes de água e energia. Os valores unitários e totais referentes às galerias estão especificados na Tabela 6.

Com a utilização das galerias técnicas, os custos para implantação das redes de água e energia elétrica se restringem à aquisição e transporte do material, assim como instalação deles dentro das galerias. Utilizando-se os parâmetros descritos anteriormente (Tabela 3), para a alocação das redes de água nas galerias técnicas no caso da operação urbana Água Branca estimou-se um valor de R\$ 427.503,69. Da mesma forma, para a rede de distribuição de energia, utilizando-se os custos descritos na Tabela 4 , chegou-se a um valor total de $\mathrm{R} \$ 1.897 .846,40$.

Finalmente, a implantação das galerias técnicas na área da operação urbana Água Branca, incluindo as redes de distribuição de água e energia elétrica em seu interior, representaria um custo total de $\mathrm{R} \$$ 40.857.562,26.

\section{Comparativo entre os custos de investimento}

Somando-se os custos referentes à implantação das redes de água e energia elétrica em valas segregadas, conseguiu-se uma estimativa total de $\mathrm{R} \$ 1$ 10.168.904,52 para implantação dessa solução na área em estudo. Para a utilização de galerias técnicas, o valor estimado é de $\mathrm{R} \$ 40.857 .562,26$, bastante superior à primeira opção, devido à necessidade de se instalar uma estrutura de grandes dimensões no subsolo, o que gera gastos maiores com quebra de pavimento existente, escavação e recapeamento. $\mathrm{O}$ elevado custo inicial pode configurar uma importante barreira para a implantação dessa alternativa, apesar das vantagens técnicas, ambientais e sociais que ela traz ao longo de seu ciclo de vida.

Deve-se acrescentar a esse fato que, devido à dificuldade de se conseguirem dados referentes aos custos de implantação e manutenção das diversas redes de serviços técnicos urbanos, analisou-se um cenário no qual somente duas redes estão inseridas dentro das galerias. Esse fato contribui para aumentar o custo inicial dessa solução, uma vez que, quanto maior o número de redes de serviços técnicos for considerado, mais serviços comuns serão necessários para alocar cada rede de forma separada, como quebra de pavimentação, movimentação de terra e recapeamento. Essa situação não ocorre no caso de se utilizarem galerias técnicas, para as quais há a necessidade de realizar apenas uma vez os serviços descritos, quando da implantação do túnel de utilidades.

Em resumo, quanto mais serviços forem considerados no estudo de viabilidade, maior a probabilidade de as galerias serem mais viáveis, pois não será preciso o desprendimento de capital para realizar diversas escavações, reaterros e obras com pavimento para a inserção das diversas redes. Em outras palavras, se os custos referentes à construção de $1 \mathrm{~m}$ linear das valas para alocar as redes de água, energia elétrica, telefonia, dados, entre outras, superarem o valor descrito para a construção de $1 \mathrm{~m}$ linear das galerias técnicas, estas poderão se tornar mais viáveis no que tange ao investimento inicial. Para o caso analisado, o custo por metro linear para a inserção das redes de água e energia elétrica de forma separada ficou em $\mathrm{R} \$ 505,25$, muito abaixo dos $\mathrm{R} \$ 2.030,02$ encontrados quando se utilizam galerias técnicas como alternativa para alocação de apenas duas redes de infraestrutura. 
Tabela 6 - Custos unitários e totais para a implantação das galerias técnicas

\begin{tabular}{|c|c|c|c|c|}
\hline Serviço & Unidade & $\begin{array}{c}\text { Custo } \\
\text { (R\$/unidade) } \\
\end{array}$ & $\begin{array}{l}\text { Quantidade } \\
\text { (unidade) }\end{array}$ & $\begin{array}{l}\text { Custo total } \\
(\mathrm{R} \$)\end{array}$ \\
\hline $\begin{array}{l}\text { Demolição de pavimento asfáltico, inclusive } \\
\text { capa; inclui carga em caminhão }\end{array}$ & $\mathrm{m}^{2}$ & 9,98 & $44.278,61$ & $441.900,51$ \\
\hline $\begin{array}{l}\text { Carga, transporte e descarga mecânica de } \\
\text { material até } 10 \mathrm{~km}\end{array}$ & $\mathrm{~m}^{3}$ & 8,60 & $9.741,29$ & $83.775,13$ \\
\hline $\begin{array}{l}\text { Escavação mecânica de valas em qualquer tipo } \\
\text { de solo exceto rochas, prof. }<4 \mathrm{~m}\end{array}$ & $\mathrm{~m}^{3}$ & 7,01 & $88.557,22$ & $620.786,08$ \\
\hline $\begin{array}{l}\text { Escoramento contínuo de madeira para galerias } \\
\text { moldadas, com reaproveitamento }\end{array}$ & $\mathrm{m}^{2}$ & 55,98 & $89.362,28$ & $5.002 .500,52$ \\
\hline Reaterro e compactação mecânica de vala & $\mathrm{m}^{3}$ & 18,06 & $8.050,66$ & $145.394,85$ \\
\hline Galeria técnica $2,00 \mathrm{~m} \times 2,00 \mathrm{~m}$ & $\mathrm{~m}$ & $1.468,01$ & $20.126,64$ & $29.546 .083,23$ \\
\hline $\begin{array}{l}\text { Execução macadame hidráulico, inclui transporte } \\
\text { de material }\end{array}$ & $\mathrm{m}^{3}$ & 156,66 & $4.427,86$ & $693.668,67$ \\
\hline Execução binder & $\mathrm{m}^{3}$ & 313,45 & $3.099,50$ & $971.539,08$ \\
\hline Execução concreto asfáltico & $\mathrm{m}^{3}$ & 446,02 & $2.213,93$ & $987.457,24$ \\
\hline $\begin{array}{l}\text { Transporte de material, binder e concreto } \\
\text { asfáltico }\end{array}$ & $\mathrm{m}^{3}$ & 7,36 & $5.313,43$ & $39.106,87$ \\
\hline & & & Total & $38.532 .212,17$ \\
\hline
\end{tabular}

Fonte: adaptado deSistema Nacional de Pesquisa e Índices da Construção Civil (2013a) e Secretaria de Infraestrutura Urbana e de Obras (2014).

A análise do investimento inicial poderia ainda ser expandida e enumerarem-se outros custos de difícil quantificação. Entre eles se incluem os custos sociais envolvidos nas atividades de instalação e manutenção da infraestrutura urbana, como os incômodos que causam as interrupções no tráfego e a dificuldade de movimentação de pedestres quando há necessidade de fazer escavações na via. Soma-se a isso a possibilidade de analisar os custos referentes à manutenção das redes, que, quando se trata de galerias técnicas, estão sujeitas a um ambiente controlado e protegido, o que prolonga a vida útil delas, diferentemente do que se observa quando as redes estão inseridas diretamente no subsolo urbano, um ambiente agressivo e imprevisível.

Além disso, é possível considerar o desprendimento desnecessário de energia toda a vez que uma rede necessite de ampliação ou reparo. Quando há redes enterradas diretamente no subsolo urbano, sempre que se necessita de alguma intervenção, há a necessidade de escavações e recapeamento, o que demanda alto consumo energético, não existente quando se utilizam galerias técnicas.

\section{Comparativo entre os custos de operação}

Para a análise comparativa dos custos operacionais, foram utilizados parâmetros publicados por Laistner e Laistner (2012) para redes de distribuição de água e energia elétrica em diversas cidades na Europa. Foram calculados valores médios com base nas diversas experiências, transformados em reais, conforme cotação do dia 16 de julho de 2013 (1 euro = 2,9615 reais), e disponibilizados na Tabela 7 .

Nota-se que, quando se utilizam galerias técnicas, os valores despendidos anualmente são consideravelmente menores. Dessa forma, é possível concluir que, a partir de determinado tempo de uso, as galerias técnicas podem se tornar mais vantajosas economicamente em relação à utilização de valas separadas, mesmo com um investimento inicial mais elevado, o que justificaria sua utilização em alguns casos.

Para a área da operação urbana Água Branca, em estudo, conhecendo-se os comprimentos totais das redes e adotando-se os custos médios obtidos com a operação das redes, conseguiu-se uma estimativa dos custos anuais desprendidos com a adoção de cada alternativa, conforme mostrado na Tabela 8 , a seguir, com base nos valores médios indicados por Laistner e Laistner (2012). Da análise dos valores, conclui-se que os custos desprendidos para a operação anual das redes de distribuição de água e energia elétrica alocadas em galerias técnicas são bastante inferiores aos das redes enterradas de forma independente.

Finalmente, foi efetuada uma estimativa de prazo de retorno dos custos de investimento, considerando-se também os custos operacionais e uma taxa de aumento anual dos preços de $6 \%$, assumindo que a inflação anual se situe em torno 
desse valor. O resultado está expresso no gráfico da Figura 4, a seguir, e a análise dos resultados mostrou que, com 7 anos de operação, as galerias técnicas se tornariam mais vantajosas economicamente para alocar as redes de água e energia elétrica quando comparado à solução de segregação em valas comuns. Adiciona-se a esse fato que se trata de uma obra de grande porte (construção de cerca de $20 \mathrm{~km}$ de túneis de utilidades), e esse período de retorno é bastante inferior às perspectivas de tempo de utilização desse tipo de instalação em uma extensa área urbana.

\section{Considerações finais}

Este estudo buscou analisar duas alternativas tecnológicas para a organização do subsolo urbano.
Da revisão bibliográfica, conclui-se que as galerias técnicas representam um meio estruturado para a ocupação do subsolo e da superfície. O subsolo, em especial, é um recurso finito, que necessita, cada vez mais, ser utilizados com eficiência, organização e segurança; portanto, ter seu uso planejado e adequadamente gerido.

A análise econômica mostrou que as galerias técnicas apresentam elevado custo inicial de implantação, o que as torna pouco viáveis quando somente analisadas sob essa condição. Em uma perspectiva de longo prazo, podem se tornar uma solução atraente do ponto de vista econômico, pelos menores custos operacionais e impactos envolvidos com manutenção e expansão de redes urbanas.

Tabela 7 - Custos anuais por metro linear de operação das redes de distribuição de água e energia elétrica

\begin{tabular}{|c|c|c|c|}
\hline \multicolumn{2}{|c|}{$\begin{array}{l}\text { Custos médios operacionais com } \\
\text { galerias técnicas ( } \mathrm{R} \$ \text { / metro linear ano) }\end{array}$} & \multicolumn{2}{|c|}{$\begin{array}{c}\text { Custos médios operacionais sem galerias } \\
\text { técnicas (R\$/ metro linear ano) }\end{array}$} \\
\hline Rede água & Rede energia elétrica & Rede água & Rede energia elétrica \\
\hline 66,80 & 65,70 & 245,34 & 106,15 \\
\hline
\end{tabular}

Fonte: adaptado de Laistner e Laistner (2012).

Tabela 8 - Custos médios anuais de operação dos sistemas técnicos urbanos quando inseridos em valas comuns e em galerias técnicas

\begin{tabular}{c|c|c|c}
\hline \multirow{2}{*}{ Serviço técnico urbano } & \multirow{2}{*}{ Comprimento total da rede $(\mathbf{m})$} & \multicolumn{2}{|c}{ Custos médios anuais (R\$) } \\
\cline { 3 - 4 } & & $\begin{array}{c}\text { Com galerias } \\
\text { técnicas }\end{array}$ & $\begin{array}{c}\text { Sem galerias } \\
\text { técnicas }\end{array}$ \\
\hline Água & \multirow{2}{*}{$20.126,64$} & $1.344 .519,50$ & $4.937 .852,17$ \\
\hline Energia Elétrica & & $1.322 .380,48$ & $2.136 .415,09$ \\
\hline
\end{tabular}

Fonte: adaptado de Laistner e Laistner (2012).

Figura 3 - Comparação entre custos totais desprendidos com as redes de serviços técnicos urbanos de água e energia elétrica quando inseridas em galerias e em valas comuns

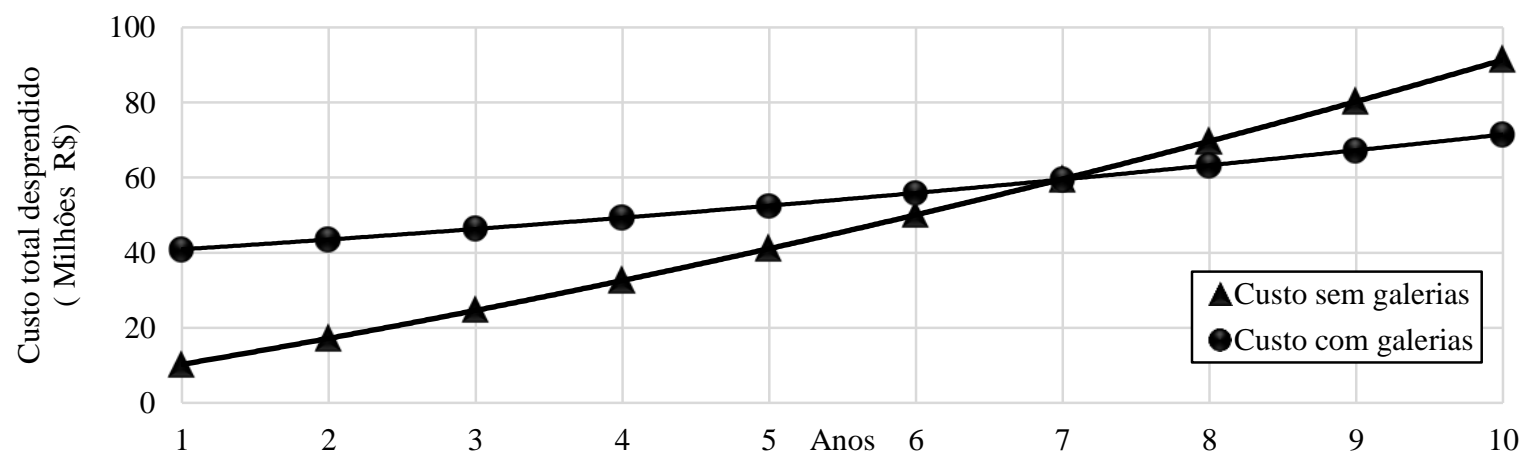


O trabalho desenvolvido mostra, por meio de estimativas de custos de investimento e custos operacionais para uma área selecionada, que a escolha da solução de organização do subsolo prescinde de uma análise mais abrangente, para que sua viabilidade real possa ser adequadamente estimada. $\mathrm{O}$ artigo indica um método geral para realizar a comparação, embora tenha sido identificada carência de dados sobre custos das múltiplas redes de infraestrutura, o que possibilitaria a execução de uma análise mais completa. Por fim, espera-se que a abordagem feita possa motivar uma análise mais abrangente das alternativas de intervenção no subsolo urbano e na disposição das redes de infraestrutura no território das cidades, e a busca por soluções alternativas que se mostrem mais adequadas a cada contexto.

\section{Referências}

\section{ASSOCIAÇÃO BRASILEIRA DE NORMAS}

TÉCNICAS. NBR 12218: projeto de rede de distribuição de água para abastecimento público. Rio de Janeiro, 1994.

\section{ASSOCIAÇÃO BRASILEIRA DE}

FABRICANTES DE TUBOS DECONCRETO.

Galerias celulares: padronização do

dimensionamento estrutural de aduelas de concreto armado pré-fabricadas, conforme Normas ABNT 15396 e 6118. São Paulo, 2012.

BESNER, J. The Sustainable Usage of the Underground Space in Metropolitan area. In: ACUUS 2002 INTERNATIONAL CONFERENCE URBAN UNDERGROUND SPACE. A RESOURCE FOR CITIES.Turim, 2002.Proceedings...Turim, Politécnico di Torino, 2002.

CANO-HURTADO, J. J.; CANTO-PERELLO, J. Sustainable Development of Urban Underground Space ForUtilities. Tunneling and Underground Space Technology, v. 14, n. 3, p. 335-340, 1999.

CANTO-PERELLO, J.; CURIEL-ESPARZA, J. Assessing Governance Issues of Urban Utility Tunnels.Tunneling and Underground Space Technology, v. 33, p. 82-87, 2013.

CANTO-PERELLO, J.; CURIEL-ESPARZA, J.An Analysis of Utility Tunnel Viability in Urban Areas.Civil Engineering and Environmental Systems, v. 23, n. 1, p. 11-19, 2006.

EMPRESA MUNICIPAL DE URBANIZAÇÃO. Operação Urbana Água Branca: parâmetros de revisão out09. São Paulo: EMURB, 2009.

GOOGLE. Google Earth Image. [Mapa da área da operação urbana Água Branca, em São Paulo]. 2013.
HUNT, D. V. L.; NASH, D.; ROGERS, C. D. F. Sustainable Utility Placement Via Multi-Utility Tunnels. Tunneling and Underground Space Technology, v. 38, p. 15-26, 2014.

HUNT, D. V. L.; ROGERS, C. D. F. Barriers to Sustainable Infrastructure in Urban Regeneration.Engineering Sustainability, v. 158, n. ES2, p. 67-81, 2005.

LAISTNER, A.; LAISTNER, H. Utility Tunnels: proven sustainability above and below ground. In: REAL CORP 2012, Lauchhein,

2012.Proceedings....Lauchhein, 2012.

MARTINARD, C. Le GénieUrbaine. Paris, 1986. Rapport au Ministre de 1'Équipment, du Logement, de l'Aménagement du Territoireet des Transports. La documentation française.

\section{RUBENS, T. F. Contribuição ao}

Dimensionamento de Rede de Distribuição de Água Por Critério de Custo Global. 2011. Dissertação (Mestrado em Engenharia Civil) Escola Politécnica, São Paulo, 2011.

\section{SECRETARIA DE INFRAESTRUTURA} URBANA E DE OBRAS. Tabela de Custos Com Desoneração, Data-Base Janeiro 2014. São Paulo: PMSP, 2014.

SISTEMA NACIONAL DE PESQUISA E ÍNDICES DA CONSTRUÇÃO CIVIL. Relatório de Serviços Com Desoneração. Rio de Janeiro: IBGE, 2013a.

\section{SISTEMA NACIONAL DE PESQUISA E ÍNDICES DA CONSTRUÇÃO CIVIL. Relatório de Insumos Com Desoneração.Rio de Janeiro: IBGE, 2013b.}

\section{SISTEMA NACIONAL DE INFORMAÇÕES SOBRE SANEAMENTO. Diagnóstico dos} Serviços de Água e Esgotos. Brasília: Ministério das Cidades, Secretaria Nacional de Saneamento Ambiental, 2012.

VELASCO, G. D. N.; LIMA, A. M. L. P.; COUTO, H. T. Z. Análise Comparativa dos Custos de Diferentes Redes de Distribuição de Energia Elétrica no Contexto da Arborização Urbana. RevistaÁrvore, v. 30, n. 4, p. 679-686, 2006.

WANG, J. H.; KOIZUMI, A.; LIU, X. Advancing Sustainable Urban Development in China.Municipal Engineer, v. 161, n. 1, p. 3-10, 2008.

\section{Agradecimento}

Ao Santander Universidades, pelo apoio recebido para o desenvolvimento desta pesquisa. 
Luis Henrique Lancellotti Zapparolli Pupin

Departamento de Engenharia de Construção Civil, Escola Politécnica | Universidade de São Paulo | Av. Prof. Almeida Prado, trav. 2 , n. 83, Cidade Universitária | São Paulo - SP - Brasil | CEP 05508-900 | Tel.: (11) 3567-9990 | E-mail: luishenrique.pupin@gmail.com

\section{Karin Regina de Casas Castro Marins}

Departamento de Engenharia de Construção Civil, Escola Politécnica | Universidade de São Paulo | Tel.: (11) 3091-5107 | E-mail: karin.marins@poli.usp.br

\section{Revista Ambiente Construído}

Associação Nacional de Tecnologia do Ambiente Construído

Av. Osvaldo Aranha, $99-3^{\circ}$ andar, Centro

Porto Alegre - RS - Brasil

CEP $90035-190$

Telefone: +55 (51) 3308-4084

Fax: +55 (51) 3308-4054

www.seer.ufrgs.br/ambienteconstruido

E-mail: ambienteconstruido@ufrgs.br 